\section{THE DEVELOPMENT OF A HEALTH DEPARTMEN'T.}

By E. H. SNELL, M.D., B.Sc., Lond., F.R.S. (ED.) Medical Officer of Health, Coventry.

(From the Annual Report on the Fealth of Coventry, 1907.)

WITH one or two exceptions the health department of a town has been a growth of quite recent development. It was in the first instance forced on all authorities by the Public Health Act of 1875. It is quite certain that if local option in this matter had been predominant, there would be a number of authorities which would still regard such a department as quite a useless redundancy. It is not surprising, therefore, to find that the functions of such a department have often been regarded as excessively limited. This accounts for the fact that in many districts, in order to appear to justify the employment of a whole-time officer as an inspector of nuisances, other quite unrelated duties have been added. In some districts this has been done by making the inspector also the surveyor, or the building inspector, or even the official having to do with the granting of licenses under the Petroleum Acts. Remnants of such an appointment exist in this city, in that your chief inspector is the inspector under the Contagious Diseases of Animals Act. This Act relates to matters which cannot be said to have any direct relation to the health of the inhabitants ; it has considerable importance from the point of view of agricultural interests, but that is another matter; the Act is under the supervision of the Board of Agriculture, a Board so active indeed that various notifications that have to be made to it have to be made by telegram: a case of a pig suffering from any illness may be at once suspected as suffering from swine fever ; information is telegraphed to the Board, and one or more inspectors from that Board immediately come down to investigate the matter. Nothing but praise can be given to such alertness, but from the point of view of the association of such adventitious work with the health department, there is this to be said, namely, that it is not a good training for sanitary inspectors, in that in the course of time they attach to the occurrence of a case of suspected swine fever among pigs, very much more importance than they. do to six cases of typhoid fever among human beings, and a very much larger amount of time and intelligence is devoted to the tracing of the cause of the swine fever. In most districts this function is allocated to the police, and I venture to opine that it is thus very much better placed than in a health department, whose energies should be better directer into other channels.

In this city there has existed a tendency to place in the health department any functions which do not definitely belong to any other department. In recent years the Shop Hours Acts have been added to that department as a part of its functions. During the past yearand $I$ am bound to add that I advised against it-the "American Gooseberry Mildew Order," 1907, of the Board of Agriculture has been added. This is an affection of gooseberries, which is neither directly or indirectly related to the health.of the community; it is of purely horticultural moment; gooseberries so affected are unsaleable; this affection of gooseberries has therefore no relationship to health. During the past year I was requested by the executive sub-committee of the sanitary committee to report on the "Fertilisers and Feeding Stuffs Act" of 1906. After considerable work I did so, and I showed that the Act, although of agricultural moment, had neither any direct nor any indirect influence on the health of the community, and no action under the Act was taken.

The administration of the Food and Drugs Act is entrusted to your sanitary committee ; yet in the main these are Acts directed towards the detection of fraud, and are therefore mostly police matters; to quite a small extent they may be said to be related to the health of the community.

During the last few months the question of the administration of the Education (Administrative Provisions) Act, 1907, has been before some of the committees of your Council, as well as before your Council itself. This is the most important Act relating to the health of the community which has had to be considered for the last thirty-three years, and the opinion has been openly advocated here that the administration of this Act should be entrusted to a new and separate department; having had some experience of both kinds of work, I venture to think that if such opinions should prevail, the real "health" department of the Corporation will in a few years be that controlled by the education committee of your Council.

[Dr. Snell's views on the relation of the Food and Drugs Acts to the health of the community will not, we think, be shared by many medical officers of health. Such matters as the impoverishment of milk and the addition of chemical preservatives to milk and other foods have a very direct bearing on public health, and should be under the control of the medical officer of health. The arsenical beer outbreak has afforded a good example of how the health of the community may suffer from chemical impurities in food.--Ed.] 